\section{South African boycott}

SIR-The officers of the Linnean Society have met to discuss the matter raised in Nature $(327,273 ; 1987)$. We endorse the view of our council that you reported in that article, and reaffirm that we shall continue our policy of considering all submissions to our journals on scientific merit alone. We are taking steps to rectify the single isolated incident of rejection to which you drew attention and intend to ensure that in future the society's agreed policy is implemented.

\section{W.G. Chaloner} (President)

The Linnean Society of London,

Burlington House, Piccadilly,

London WIV OLQ, UK

\section{Turin Shroud}

SIR-I can assure Denis Dutton (Nature $327,10 ; 1987)$ that all the participants in the workshop on "Radiocarbon Dating of the Turin Shroud" are acutely aware that the operation must be completely credible.

The workshop at Turin from 29 September to 1 October last year, chaired by Professor Carlos Chagas in his capacity as president of the Pontifical Academy of Sciences, involved representatives of the seven laboratories that will make the measurements, the British Museum, the Archbishopric of Turin and a representative of the Abegg-Stiftung in Bern, who will remove the sample from the shroud.

I presented the conclusions and procedural steps agreed to at the workshop as a poster at the International Symposium on Accelerator Mass Spectrometry at Niagara-on-the-Lake, Ontario, on 27-30 April. It will be followed by a paper to appear in Nuclear Instruments and Methods.

The procedures recommended are clearcut and straightforward. Although the testing laboratories will follow blind carbon-dating procedures, there will be no possibility of "tampering" with the shroud samples except as a result of collusion by a number of organizations including the British Museum, the Pontifical Academy of Sciences and the Archbishopric of Turin. The removal of the shroud sample by a noted textile expert from the Abegg-Stiftung in Bern, Switzerland, will be witnessed by representatives of the seven carbon-dating laboratories. A representative of the Pontifical Academy, the British Museum and the Archbishopric of Turin will supervise the shroud samples from their removal to their delivery, together with a dummy sample and control samples, to each representative of the seven laboratories. Equally careful procedures will attend the final analysis of the results from the seven laboratories. Six of the seven laboratories have already participated in blind interlaboratory comparison measurements supervised by the British Museum.

It is clearly important that the most significant scientific test on the Shroud of Turin, radiocarbon dating of the cloth, should be carried out in a manner that will convince people like Dutton that the results, whatever they may be, are believable. The only interest of the participating carbon-dating laboratories in "confidentiality" is that they be able to carry out the measurements under reasonably serene conditions.

Harry E. Gove

Nuclear Structure Research Laboratory, University of Rochester,

Rochester, New York 14627, USA

\section{Scientific fraud}

SIR-Walter Stewart and Ned Feder (Nature 325, 207-214; 1987) give the results of a detailed analysis of 109 publications written by Dr John Darsee over a period of about three years. Their stated objective was to throw light on the vigilance of referees, editors of journals and Darsee's co-authors in meeting the standards conventionally accepted as necessary in the scientific literature.

Having catalogued all the errors and lapses of normal standard that they can find in these publications, the authors imply that these errors could have been avoided if the co-authors, editors and referees had been sufficiently vigilant. Unfortunately this is often not true, as their own paper shows. One of their criticisms of one of Darsee's papers is: "The summary of the paper gives the urinary taurine levels of the family members with congestive cardiomyopathy as ranging from 411 to $536 \mathrm{mg}$ taurine per $\mathrm{g}$ creatinine, but the text and Table 1 of the same paper give for the same measurement $426 \pm 45 \mathrm{mg}$ taurine per $\mathrm{g}$ creatinine (mean \pm standard deviation). Simple inspection suggests that these two sets cannot simultaneously be valid." This is described as a "major error which is fundamental and call[s] into question the validity of the paper's main conclusions. More typically, however, the errors simply reflect on the care with which the paper had been prepared." Unfortunately, the authors are wrong as simple inspection does not suggest the conflict between these data items. In fact, if we use the admittedly extreme data values of $410.51,410.51,410.51,410.51$, $410.51,410.51,410.51$ and 536.49 , we get (to the nearest integers) a range of 411 to 536 and a mean \pm s.d. of $426 \pm 45$.

This example raises two immediate questions. The most obvious is that it brings into question the authors' detailed count of errors and lapses from the 109 publications that they reviewed. More important, however, is that it brings into question their assumption that this type of error can be avoided if suitable care is taken by editors, reviewers and the coauthors of publications. As the editors discuss in Nature $(\mathbf{3 2 5}, \mathbf{1 8 1} ; \mathbf{1 9 8 7 )}$ and Barbara Culliton discusses in Science (235, 422 ; 1987), this paper has been under extraordinary study for over three years, but it still contains an error that the authors would classify as a type 1 lapse, "explicable simply by carelessness of excessive haste".

If the results of the Stewart and Feder paper are to be used, the listing of the errors and lapses that have been found by them must be independently audited by outside reviewers, as many of the small number that they have released have been questioned. Eugene Braunwald (Nature 325, 215-216; 1987) analyses many suggested errors or lapses, and also states that Stewart and Feder have refused to release the specifics and location of their purported errors from Darsee's papers. Without this release and a subsequent independent analysis (particularly by Darsee's coauthors), I cannot see how their detailed data can be used.

J. Denbigh Starkey

Department of Computer Science,

Montana State University,

Bozeman, Montana 59717, USA

\section{Crystal clear}

SIR-I should like to comment on the critical review by J. W. Emsley ( Nature 323, 377 ; 1986) of our new publication, Molecular Crystals and Liquid Crystals Bulletin, and of our decision to issue separately $M C L C$ Letters.

The criticism neglected to mention that MCLC Bulletin is distributed at no cost to all subscribers to the parent journal. It also does not make it clear that we have had a Letters section for some time, and simply decided to make it available as a separate optional subscription item rather than an obligatory part of a subscription to the parent journal. The parent journal $M C L C$ appears monthly and contains papers dealing with liquid crystals, lowdimensional solids, molecular crystals, and (being added in 1987) nonlinear optical phenomena. The journal was established in 1966, and periodically introduces new services. Free services hardly deserve to be judged by the same criteria one applies to journals. Creating options should not be judged as an attempt at price escalation.

Gordon and Breach Science

Martin B. Gordon

Publishers Ltd,

1 Bedford Street,

London WC2E 9HD, UK

Letters submitted for Correspondence should be typed, double-spaced, on one side of the paper only. 